\title{
El Canal del
}

Congreso, análisis

de sus alcances y

limitaciones a veinte

años de transmisiones*

/ The Congress

Channel, an analysis

of its achievements

and limitations

after twenty years

of broadcasting

* Artículo de investigación. Recibido: 8 de marzo de 2018. Aceptado: 17 de abril de 2018. Tla-Melaua, revista de Ciencias Sociales. Facultad de Derecho y Ciencias Sociales. Benemérita Universidad Autónoma de Puebla, México / E-Issn: 2594-0716 / Nueva Época, año 12, núm. 45, octubre 2018-marzo 2019, pp. 104-128. 
Enrique Castañeda Tenorio*

Alicia Hernández de Gante**

Ricardo Ibrahim Huerta Casco***

\section{RESUMEN}

El siguiente trabajo analiza la importancia del Canal del Congreso como medio de comunicación masiva, que entre otras cosas; puede construir, modificar o influir en la percepción ciudadana u opinión pública. En este sentido, se desmenuza el diseño institucional del Canal del Congreso a través de la normatividad vigente y lo que ha significado la obligatoriedad de incluir a todas las fracciones parlamentarias del Congreso de la Unión en su órgano máximo de gobierno. Se presentan los atisbos de profesionalización del trabajo del Congreso, pero al mismo tiempo el poco interés por innovar, producir y presentar una programación atractiva para su teleaudiencia. Se deja claro, que mientras no existan modificaciones estructurales y políticas en el Canal del Congreso; su visibilidad, proyección e impacto serán ínfimos. De esta forma, se deja claro, que incumpliría con el objeto primordial del Canal, como difundir el trabajo parlamentario.

\section{PALABRAS CLAVE}

Canal del Congreso, medio de comunicación, diseño institucional.
A B S T RAC T

The following academic work analyzes the importance of the Congress Channel. Since, it represents a way of mass communication that modifies, builds and influences public perception and opinion. In this sense, the institutional design of the Congress Channel is broken through the current regulations. The broadcast has to include all the parliamentary fractions of the Congress of the Union, in its maximum body of government. The duty was to provide an insight of how the Congress carries out its activities. The lack of interest to innovate as to produce and present a program that can interest the audience. It is clear that, as long as there are no structural and political modifications in the Congress Channel, its audience view, projection and impact will be insignificant. In this way, it fails to fulfill its primary objective: the dissemination of parliamentary work.

KEYWORDS

Channel of the Congress, means of communication, institutional design.

\footnotetext{
* Profesor investigador en la Facultad de Derecho y Ciencias Sociales de la Benemérita Universidad Autónoma de Puebla. México. (castenorio@outlook.com) orcid.org/0000-0003-1159-0002

** Profesora investigadora en la Facultad de Derecho y Ciencias Sociales de la Benemérita Universidad Autónoma de Puebla. México. (aliciahdegante@gmail.com) orcid.org/0000-0001-7026-0738

*** Estudiante de la Licenciatura en Administración Pública y Ciencias Políticas en la Facultad de Administración de la Benemérita Universidad Autónoma de Puebla, México. (ricardohcasco@gmail.com) orcid.org/0000-0002-2807-2773
} 

diseño y funcionamiento del Canal del Congreso / 4. Alcances y limitaciones del Canal del Congreso / 5. El Canal del Congreso: programación / 6. Conclusión / 7. Bibliografía

\section{INTRODUCCIÓN}

Tradicionalmente, el Congreso de la Unión no representó un papel determinante en la política mexicana. Esto en parte se debe a la evolución del sistema político mexicano que articuló, formó y fomentó un Poder Ejecutivo fuerte. El presidencialismo, eje rector de casi todos los aspectos políticos e institucionales, hizo del Congreso de la Unión - y en particular, de la Cámara de Diputados - un actor débilmente institucionalizado, con una imagen de descrédito entre la ciudadanía en general. ${ }^{1}$

Los procesos de liberalización democrática, como la instauración del sistema de diputados de partido (1963), la representación proporcional (1977), la pérdida de mayoría calificada del partido hegemónico (Partido Revolucionario Institucional, en 1988), y pérdida de mayoría absoluta en la Cámara de Diputados (1997), hicieron posible un nuevo diseño institucional. A partir de 1997, como consecuencia del proceso de liberalización en México, el Canal del Congreso inició transmisiones, regulado por la Ley Orgánica del Congreso General de los Estados Unidos Mexicanos de 1999.

El análisis de las instituciones a partir de la norma, entendidas éstas como las reglas del juego en una sociedad, nos permite entender el cambio formal y sus resistencias a través de costumbres, tradiciones y códigos de conducta. ${ }^{2}$ Los alcances y los límites del Canal del Congreso se expondrán al analizar la evolución de la propia norma y los factores políticos que, por tradición o códigos de conducta firmemente arraigados, impiden su desarrollo pleno.

\footnotetext{
${ }^{1}$ En una análisis de 2002 a 2011 sobre las percepciones de las y los mexicanos en el Congreso de la Unión, hay una tendencia cada vez mayor a la desaprobación tanto del trabajo de los senadores como de los diputados. Llega a un nivel cercano a 60\% para ambas cámaras. De la O López, Felipe, La percepción de las y los mexicanos en el Congreso de la Unión, México, Instituto Belisario Domínguez, 2017. La Consulta Mitofsky, en el análisis de diversas instituciones en 2015, señaló que el índice de confianza para los senadores es de 5.3 y para diputados 5.2. Las universidades en comparación recibieron 7.3 en el índice de confianza. Mitofsky, "México: Confianza en Instituciones, 2015", Consulta. Disponible en: http://consulta.mx/index.php/estudios-e-investigaciones/mexico-opina/item/575-confianza-eninstituciones

${ }^{2}$ North, Douglass, Instituciones, cambio institucionaly desempeño económico, México, Fondo de cultura Económica, 1995, pp. 7-22.
} 
La redacción original de la Ley Orgánica del Congreso General de 1999³ señala que el Canal del Congreso de la Unión es un órgano de difusión de la actividad legislativa, el cual contribuiría a la información, el análisis y las discusiones amplias y públicas de la situación nacional, vinculadas con la actividad legislativa. La redacción actual, retoma los puntos ya establecidos, más la difusión de la actividad parlamentaria a través de dicho medio como objetivo principal.

La importancia del Congreso de la Unión, a través del Canal, representa una oportunidad innovadora para difundir el trabajo legislativo. Sin embargo, el Canal corre el riesgo de no involucrar a los ciudadanos en lo público y, con ello, de convertirse en un espacio vacío ${ }^{4}$ que limita su espacio de acción política.

Así, lo esencial de los medios de comunicación como Canal del Congreso radica no sólo en la forma de dar a conocer lo que se desea, sino los procesos que se siguen en la institución para cumplir sus objetivos. Por tanto, los medios de comunicación como la televisión son determinantes, pues, a través de ellos, consciente o inconscientemente, se puede imponer una forma de ver la realidad. ${ }^{5}$

El inicio del trabajo del Canal del Congreso marca un antes y un después en el Poder Legislativo, principalmente por la posibilidad de alcanzar espacios antes vedados para fuerzas minoritarias y lograr obtener, a través de sus transmisiones, un mayor alcance en la población mexicana.

A poco más de veinte años de que hayan iniciado sus trasmisiones, se hace necesario analizar la norma en la cual se estructura, organiza y funciona actualmente el Canal, así como determinar si la programación y contenidos son determinantes para denotar la importancia del mismo: la difusión del trabajo parlamentario.

Así, el objetivo del presente trabajo consiste en determinar si los alcances y limitaciones del Canal del Congreso, a través del análisis de la normatividad, son los idóneos o si tendrían que adaptarse a un nuevo modelo estructural en torno a su labor esencial. También se analizará si las acciones emprendidas en materia de programación coadyuvan a la difusión y, por ende, a potenciar el trabajo conjunto del Poder Legislativo.

En el presente trabajo, se describen los alcances y límites del Canal del Congreso a partir de las atribuciones, facultades y estructura que la propia norma le proporciona. Se indican algunas posibles causas de que el Canal no

\footnotetext{
3 "Ley Orgánica del Congreso General de los Estados Unidos Mexicanos", Diario Oficial de la Federación, 31 de diciembre, 1999; "Ley Orgánica del Congreso General de los Estados Unidos Mexicanos", Diario Oficial de la Federación, 28 de diciembre, 2017. Disponible en: http://www.diputados.gob.mx/LeyesBiblio/ ref/locg.htm

${ }^{4}$ Cansino, César, México en ruinas. Los saldos del panismo en el poder 2000-2012, México, Benemérita Universidad Autónoma de Puebla - Juan Pablos Editor, 2014, p. 65.

${ }^{5}$ Zaragoza Ramírez, Mario Alberto, "Democracia y comunicación política", en Felipe López Veneroni (coord.), El concepto de cultura política y los medios de información en México, México, unaM, 2009, p. 107.
} 
haya logrado su objetivo principal. Por otra parte, a falta de análisis puntuales sobre el tema, se retoman algunos artículos de investigación, libros, fuentes periodísticas y estadísticas, para fundamentar lo aquí vertido, e incluso como referente más cercano al medio, se hace una pequeña comparación con su canal hermano, el Canal Judicial.

\section{UN BREVE ALCANCE TEÓRICO}

Para analizar el papel del Canal del Congreso como medio de comunicación, es necesario precisar algunas ideas alrededor de nuestro objeto de estudio. Una definición globalizadora que nos introduce a nuestra temática es que "la importancia de la comunicación política radica en el derecho de réplica de la opinión pública respecto a las acciones de los políticos [...] en el campo de la democracia". ${ }^{6}$ Así, la comunicación por sí misma necesita de un medio para transmitir su mensaje y, por el otro, un receptor. Cuando el mensaje que se trasmite a través del medio contiene acciones, trabajo u opiniones de gobierno, conjugamos las dos variables: comunicación y política.

La comunicación política como medio que transmite acciones en un sentido amplio de gobierno genera una opinión en los receptores. La opinión pública entendida como una reacción, respuesta, expresión o juicio frente a una declaración o pregunta, ${ }^{7}$ conjuga las tres variables que integran comunicación, política y opinión pública.

El Canal del Congreso se estudiará desde una perspectiva analítica institucional, es decir desde la evolución de la institución a través de las reglas del juego, en un marco de transición y apertura democrática. ${ }^{8}$ Por ello, no se tratará desde un marco externo, ligado a la comunicación política, a la opinión pública o incluso a la cultura política. Sin embargo, es necesario aclarar que, para establecer los límites y sus alcances, se retomarán algunas variables de dichos enfoques de estudio, como índice de audiencia, programación y percepción ciudadana del Canal del Congreso.

El proceso de apertura democrática en México es el punto de partida para iniciar nuestro análisis. "La Cámara de Diputados es, sin lugar a dudas, el ámbito institucional que ha funcionado como motor de la transformación de la democracia en México." ${ }^{99}$ El Reglamento del Canal de Televisión del Congreso General de los Estados Unidos Mexicanos define al Canal como

\footnotetext{
${ }^{6}$ Reyes Montes, María Cristina, O’Quínn Parrales, José Antonio, Morales y Gómez, Juan Miguel, Rodríguez Manzanares, Eduardo, "Reflexiones sobre la comunicación política", Espacios Públicos, vol. 14, núm. 30, p. 100.

${ }^{7}$ Bobillo, Francisco, "La opinión Pública", Revista de Estudios Políticos, núm. 58, p. 40.

${ }^{8}$ North, Douglass, op. cit., pp. 7-22.

${ }^{9}$ Lujambio, Alonso, El poder compartido. Un ensayo sobre la democratización mexicana, México, Océano, 2000, p. 33 .
} 
"un medio de comunicación del Estado que depende del Poder Legislativo y que pertenece a la nación", ${ }^{10}$ si bien la propia ley indica que el Canal es independiente y autónomo, no deja de ser una institución dependiente de los intereses de los partidos políticos y de los grupos parlamentarios presentes en el Congreso de la Unión.

Hoy en día, los medios de comunicación clásicos son de vital importancia, principalmente por sus alcances mediáticos, contenidos y la calidad de los mismos. Todos los medios de comunicación, televisión, radio, periódicos e internet, se han convertido en el espacio privilegiado de la política, no sólo por la posibilidad de obtener o ejercer el poder, sino porque, a través de los medios, la política puede producir imágenes y sonidos que orienten o manipulen simbólicamente a quienes los ven y los escuchan. ${ }^{11}$

En este contexto, existe la posibilidad de convertir al Canal del Congreso en un instrumento para la difusión de un poder en específico: el Poder Legislativo, de modo que se generen o modifiquen percepciones a favor de la institución y del Estado mismo. El Canal por tanto, marca un hito en la historia reciente del Congreso, en contraposición al papel que había desempeñado hasta hace poco.

La evolución y desarrollo de la televisión en México siempre ha jugado un papel importante en la vida política de nuestro país, principalmente por lo que ha representado, en general, y Televisa, en particular. Como marco de referencia para denotar la importancia que el medio jugaría en la vida política del país, y por tanto del Estado, el 1 de septiembre de 1950, el primer canal comercial en México inició sus transmisiones con la lectura del IV Informe de Gobierno del Presidente Miguel Alemán Valdés. Esto dio paso a la consolidación e influencia de los medios a través de un partido político (Partido Revolucionario Institucional) en todo el entramado institucional.

Hasta el momento, el rol del Canal del Congreso sigue estando sumamente limitado, denostado, soslayado y casi oculto ante la población en general por sus alcances que mostraremos en este artículo. Como muestra la encuesta nacional de vivienda, aplicada en 2013 por la empresa Parametría. Cuando pregunta "¿Usted sabía que actualmente existe un canal donde se transmiten las sesiones y discusiones que se dan en la Cámara de Diputados y Senadores?", $54 \%$ respondió que no sabía. Para este momento, las trasmisiones del Canal

\footnotetext{
10 "Reglamento del Canal de televisión del Congreso General de los Estados Unidos Mexicanos Artículo 3", Diario Oficial de la Federación, 8 de marzo, 2017. Disponible en: http://www.dof.gob.mx/nota_detalle.php? codigo $=5475476 \&$ fecha $=08 / 03 / 2017$

${ }^{11}$ Castells, Manuel, "La era de la información", Economía, Sociedad y Cultura. El poder de la identidad, vol. 2, México, Siglo XXI, 2004, p. 343.
} 
del Congreso aún se realizaban por televisión restringida (televisión de paga), y gran parte de la población desconocía la existencia del mismo. ${ }^{12}$

En este mismo sentido, en la encuesta aplicada en octubre de 2017 por Berumen y Asociados, a la pregunta “¿Usted ha visto alguna vez el Canal del Congreso?", sólo 41.3\% de los encuestados mencionó que sí. ${ }^{13}$ Los datos arrojados a través de distintas encuestadoras, en distintos momentos, son alarmantes. Además de que el Canal no es conocido, casi 60\% de quienes lo conocen no lo ven.

En la práctica, el Canal es insuficiente, como estrategia de comunicación, de posicionamiento o incluso como formador de opinión sobre el trabajo de los legisladores. Sólo se ha limitado a transmitir parcamente el trabajo de los legisladores y, en pocas ocasiones, ha creado contenido innovador.

La estrategia, por otra parte, no es sólo mostrar la casa, los vidrios, los ladrillos, las ventanas y las puertas, como señala Jaime Durán Barba. La estrategia es un plan integral en el que cobra sentido todo lo que hace y deja de hacer el gobierno, como conseguir metas concretas, dejando atrás la vanidad de los que nos representan. ${ }^{14}$

Lo que cobra sentido en estos veinte años de trasmisión del Canal es que pocas veces se ha contado con un plan integral para, a través de la norma, estructurar un órgano independiente, con capacidad de decisión apartidista y largo alcance que modifique percepciones y difunda el trabajo parlamentario. Además, no se han detenido a analizar que el diseño institucional impide el crecimiento y desarrollo del medio. La reforma de la Ley Orgánica del Congreso General de los Estados Unidos Mexicanos hizo que los trabajos del Canal se sujetaran más a metas políticas y de intereses de fracciones parlamentarias, que a metas concretas de eficiencia y calidad. ${ }^{15}$

La pluralidad de fracciones parlamentarias en los trabajos de la Cámara de Diputados, y por ende del Canal del Congreso, en parte ocasionan la falta de posicionamiento. Así, se verifica que el Canal no cuenta con un crecimiento sostenido ni planes de largo alcance que reestructuren su funcionamiento.

\footnotetext{
12 "La mayoría de la población no sabe que existe el Canal del Congreso", Parametría, 2013. [Consulta: 16 de enero, 2018]. Disponible en: 000www.parametria.com.mx/casta_parametrica.php?cp=4641

13 "Estudios de opinión pública 2017 Canal del Congreso", Canal del Congreso, octubre, 2017. [Consulta: 17 de enero, 2017]. Disponible en: www.canaldelcongreso.gob.mx/transparencia/focalizada/ciudadanía ${ }^{14}$ Durán Barba, Jaime, "La estrategia de la comunicación", en Roberto Izurieta (coord.), Estrategias de comunicación política para campañas y gobiernos, México, The George Washington University - Benemérita Universidad Autónoma de Puebla, 2008, pp. 23-26.

${ }^{15}$ Los artículos 17, 18, 22 y sus numerales distribuyen los órganos de dirección de la Cámara de Diputados (mesa directiva, junta de coordinación política, comisiones, etcétera) de forma plural. Desde 1997 a la fecha, los órganos de dirección de la Cámara de diputados se han repartido anualmente entre el Partido Acción Nacional, Partido Revolucionario Institucional y el Partido de la Revolución Democrática. Así, se dejó en claro que los intereses de partido se superponen de año en año en la organización interna del Congreso y por ende del Canal del Congreso.
} 
Por otra parte, coincidimos con Roberto Izurieta en que las estrategias deben ir más allá de la simple elaboración de un plan de trabajo. El autor menciona que, si el plan no se acompaña de investigación, clasificación de las audiencias, construcción del mensaje, cobertura, entre otros, no hay tal plan. ${ }^{16} \mathrm{~A}$ todas luces, lo que necesita el Canal para crecer y desarrollarse es ese plan que contemple lo ya señalado.

Algunos estados de la república, a través de sus congresos locales, han iniciado trasmisiones donde exponen sus labores legislativas, principalmente con la firma de convenios con televisoras locales. Ejemplo de ello son el estado de Oaxaca, Morelos, Ciudad de México, entre otros. Esto denota la importancia de la norma cuando les permite a los congresos locales la firma de convenios, así como dar a conocer el trabajo de los legisladores a través de los medios masivos de comunicación. ${ }^{17}$

Así, el alcance de metas, acuerdos o convenios, a través de proyectos bien esturados y definidos, demuestra la importancia de los medios de comunicación y de una normativa puntual y actualizada. Es menester que cualquier institución que desee aproximarse a una ciudadanía cuente cada vez con más espacios de calidad e innovación. La mejora de lo que se trasmite en medios de comunicación como el Canal del Congreso fortalecería la difusión del trabajo legislativo, así como la posibilidad de cambiar percepciones, de negativas a positivas.

\section{ESTRUCTURA, DisEÑO Y FUnCIONAMIENTO DEL CANAL DEL CONGRESO}

Los mexicanos, o al menos una parte, se aproximan al quehacer diario de los legisladores a través de un medio masivo de comunicación tan importante como la televisión. A partir de la pluralidad partidaria, en 1997 en la Cámara de Diputados, se hizo necesaria la transformación del entramado institucional de un Poder Legislativo que había vivido a la sombra de un presidencialismo exacerbado. El Canal del Congreso inició transmisiones en 1998, con lo cual quedaron en evidencia las tareas de los legisladores, desde uno de los medios de comunicación más importantes de la historia.

A partir del rediseño y transformación de nuestras instituciones, surgió la pregunta que tantos mexicanos se han hecho durante varias décadas. ¿Qué hacen nuestros representantes en el Congreso de la Unión? Para Luisa Bejar

\footnotetext{
${ }^{16}$ Izurieta, Roberto, "La estrategia de comunicación", en Roberto Izurieta (coord.), Estrategias de comunicación política para campañas y gobiernos, México, The George Washington University - Benemérita Universidad Autónoma de Puebla, 2008, pp. 89-102.

${ }^{17}$ En la actualidad son pocos los trabajos que se han elaborado para analizar el papel que desempeñan las televisoras de los parlamentos, sin embargo ya hay más visibilidad y confronte no sólo a nivel nacional, sino también en los estados.
} 
Algazi ${ }^{18}$ el ciudadano tiende a ignorar aquello que se aleja de su ámbito personal y, por ende, tampoco es fácil comprender a simple vista lo que ahí sucede. El escaparate que ahora representa el Canal de Televisión del Congreso tiende a hacer un poco más visible el actuar de nuestros representantes, develando tareas y acciones antes desapercibidas.

Las transmisiones del Canal del Congreso evidencian la asistencia, participación, discusión, análisis y debates en los que participan los legisladores mexicanos. Sin embargo, a pesar de los esfuerzos en materias de rediseño institucional, aún es difícil señalar que el proceso de comunicación entre el ciudadano de a pie y nuestros legisladores haya mejorado. La zanja que aún queda entre ciudadanos y representantes restringe el alcance de lo que el Congreso hace, en general.

A pesar de las dificultades políticas que ha enfrentado nuestro país, como resultado del proceso de apertura democrática, los medios de comunicación, a finales del 2000, representaron y representan hoy en día un elemento cada vez más importante para la ciudadanía. Según Castells, "la política informacional como el dominio de la televisión, la mercadotecnia informatizada, el sondeo inmediato como instrumento de navegación política, la difamación como estrategia política entre otros, es un buen indicador de los tiempos que vendrán". ${ }^{19}$

Así, los medios son esenciales, como instrumentos o estrategia de posicionamiento. $\mathrm{Al}$ respecto, el entramado institucional del Canal del Congreso es determinado por las reglas que establece la Ley Orgánica del Congreso General de los Estados Unidos Mexicanos (LOCG). Esta ley, en sus inicios y hasta 2018, ha agregado cambios significativos. La primera ley concentraba los trabajos del Canal, sólo en la Comisión Bicamaral. Ahora, la nueva ley incluye una Dirección General del Canal, un Consejo Consultivo y una Defensoría de Audiencia.

El 18 de mayo de 2005 se publica en el Diario Oficial de la Federación el Reglamento del Canal de Televisión. Dentro de los cambios estructurales del Canal, se renombra como "Canal de Televisión del Congreso General de los Estados Unidos Mexicanos". Asimismo, la LOCG "reconoce las distintas plataformas de comunicación," lo que da sentido amplio y acorde al avance tecnológico. En este sentido, da paso a los medios de comunicación utilizados en la red, como Facebook, Twitter, Instagram y otras plataformas de comunicación similares a través de internet.

Con respecto al antes y después, el actual objeto del Canal va más allá de difundir la actividad legislativa. La normatividad indica que no

\footnotetext{
${ }^{18}$ Béjar Algazi, Luisa, ¿Qué hacen los legisladores en México? Élites parlamentarias en México. Los presidentes de Comisiones, México, unam - Miguel Ángel Porrúa, 2009, p. 10.

${ }^{19}$ Castells, Manuel, op. cit., p. 344.
} 
sólo se limita a mostrar el trabajo legislativo, sino a debatir, cuestionar y evidenciar los problemas de la realidad nacional, la cultura democrática y los valores nacionales. ${ }^{20} \mathrm{El}$ ir más allá, a través de la adecuación de la norma es un paso alentador y con visión de los legisladores. Sin embargo, no hay un avance significativo en los propósitos del Canal, pues, conforme a los estudios estadísticos ya citados, los ciudadanos no sólo no conocen el Canal, sino que no lo ven.

La LOCG del 28 de diciembre de 2017, en el artículo 140 y sus numerales, le dan al Canal del Congreso autonomía técnica y de gestión para cumplir con sus actividades. Sin embargo, la autonomía se pone en entredicho cuando la designación y permanencia del director del Canal depende de la Comisión Bicamaral, la cual, por ley, es un órgano de reparto partidario, con intereses particulares, según el partido político del que se trate.

La posibilidad de contar con un presupuesto propio y de gestión, facilita la toma de decisiones del Canal, pero de igual forma, ello depende de una voluntad política, que al parecer no deja de ser eso: voluntad. La facultades del Canal del Congreso denotan la importancia que los legisladores le han otorgado. Sin embargo, los lastres ya señalados no permiten una planificación a largo plazo y los vaivenes de las fuerzas políticas en ambas cámaras constriñen las metas serias y de larga data.

Los pendientes, por tanto, estarían centrados en replantear no sólo la estructura del Canal mismo, sino reflexionar sobre su autonomía, la cual, actualmente, es sólo técnica. El reto para las futuras legislaturas giraría en torno a dicha autonomía, aún sujeta a los vaivenes partidarios.

El órgano máximo de dirección del Canal del Congreso es la Comisión Bicamaral y la forma en la cual se integran los órganos de dirección del Canal es muy similar a la conformación de la Junta de Coordinación Política de la Cámara de Diputados. ${ }^{21}$ En el caso de la Comisión Bicamaral, sus integrantes son electos por el pleno de cada Cámara, a propuesta de las respectivas juntas de coordinación política. Los legisladores representan a los grupos parlamentarios de ambas Cámaras. ${ }^{22}$

La estructura del Canal de Televisión del Congreso, en su forma actual, muestra el interés por hacer del mismo un órgano especializado, con estructura y capital humano suficiente para llevar a cabo las tareas sustanciales. Sin embargo, a pesar de ser un factor en pro del trabajo de los legisladores, los

\footnotetext{
20 "Ley Orgánica del Congreso General de los Estados Unidos Mexicanos", Diario Oficial de la Federación, 3 de septiembre, 1999; "Ley Orgánica del Congreso General de los Estados Unidos Mexicanos", Diario Oficial de la Federación, 28 de diciembre, 2017. [Consulta: 22 de enero, 2018]. Disponible en: www. camaradediputados.gob.mx

${ }^{21}$ Ley Orgánica del Congreso General de los Estados Unidos Mexicanos. Reglamento del Canal de televisión del Congreso General de los Estados Unidos Mexicanos 2005, 1999, art. 31.

${ }^{22}$ Idem, artículo 141.
} 
integrantes de la Comisión Bicamaral representan los intereses de los grupos parlamentarios - partidistas - de ambas Cámaras en el Canal del Congreso.

$\mathrm{El}$ análisis de cada una de las dependencias que lo conforman es primordial para determinar cuáles son las tareas en la construcción de un diseño institucional. Éste, así, ha de contribuir no sólo a la eficacia de la labor que ahí se realiza, sino que además ha de permear profesionalmente el trabajo de los legisladores.

La Comisión Bicamaral, órgano máximo de dirección del Canal, está integrada por seis miembros, tres emanados de la Cámara de Diputados y tres de la de Senadores. ${ }^{23}$ Cuenta con una mesa directiva integrada por un presidente y dos secretarías. La mesa directiva se elige de forma directa por sus integrantes y la presidencia es anual y rotatoria entre los grupos parlamentarios y las Cámaras.

La Comisión Bicamaral, por ley, tiene la obligatoriedad de reunirse por lo menos una vez al mes. En las decisiones que ahí se toman, se debe privilegiar el consenso o, en su defecto, llegar a aprobación de los acuerdos a través de una mayoría simple.

En la LXIII Legislatura (2015-2018), la Comisión Bicamaral del Canal de Televisión del Congreso, se integró por:

- Presidente: senador Jesús Casillas Romero. Partido Revolucionario Institucional (PRI)

- Secretario: diputado Armando Soto Espino. Partido de la Revolución Democrática (PRD)

- Secretario: diputada, María Verónica Agundis Estrada. Partido Acción Nacional (PAN)

- Integrante: senador Alejandro de Jesús Encinas Rodríguez (Sin grupo parlamentario)

- Integrante: senador Daniel Gabriel Ávila Ruíz (PAN)

- Integrante: diputado Tristán Manuel Canales Najjar (PRI)

La Comisión Bicamaral tiene una composición plural: tres senadores, tres diputados y todos ellos representan a sus fracciones parlamentarias (PAN, PRI y PRD). Cabe señalar que el senador Encinas pertenecía al PRD, antes de renunciar a su militancia partidista.

A primera vista, la integración de la Comisión Bicamaral da cuenta de la equidad en la representación de las fracciones parlamentarias, pero de igual manera, muestra una correlación de fuerzas entre las distintas fracciones que pone en evidencia los intereses de cada uno de los partidos políticos. La aprobación de leyes, acuerdos o incluso la integración de la Cámara de

\footnotetext{
23 "Reglamento del Canal de Televisión del Congreso General de los Estados Unidos Mexicanos", op. cit.
} 
Diputados y de la distribución de los órganos de dirección, han representado desde la alternancia (1997) un conflicto constante. ${ }^{24}$

Sin embargo, la no existencia de un sector preponderante cargado hacia un partido político en particular denota esta serie de conflictos interpartidarios desde 1997. ${ }^{25}$ Además, la estructura del Canal permite no sólo la representación de ambas cámaras, sino que los grupos parlamentarios más representativos participen e intervengan en sus órganos de dirección.

$\mathrm{El}$ órgano de dirección principal tiene un sinnúmero de atribuciones y facultades. Una de la más sobresaliente por su carácter político - más que legal - es la posibilidad de que los integrantes de la Comisión Bicamaral decidan, a través de convocatoria pública y abierta, al titular de la dirección general. Además, la Comisión, si así lo decide, también podrá remover al director conforme a sus intereses. En lo que respecta a la programación, será el Director General del Canal quien presente la misma a la Comisión Bicamaral, y esta última quien decida si la agenda tiene luz verde o no. Todo ello limita la libertad de acción del director general.

Por otra parte, la constante en el análisis de la norma de los órganos de dirección del Canal del Congreso es la observancia de los principios de "transparencia, pluralidad, equidad, inclusión, imparcialidad y participación". ${ }^{26}$ Esto implica un avance más o menos significativo en principios, que concuerdan con su objeto principal, como medio de comunicación del Poder Legislativo.

En lo que respecta al director general, su labor es coordinar los trabajos del Canal, su encargo es de cuatro años y cuenta con una sola posibilidad de ser reelegido. Si bien, es de esperarse que dicha posición implique un sesgo político, el reglamento del Canal señala expresamente, en el artículo 17, que el interesado no deberá haber sido dirigente de algún partido político, candidato a cargo de elección popular o de alguna agrupación política nacional en los últimos cinco años anteriores a su designación.

No obstante, las restricciones políticas expuestas en el reglamento no impiden que el seleccionado sea militante de algún partido político, algún funcionario o exfuncionario de alguna institución política. Lo loable del reglamento es que también alienta la profesionalización de quien ocupe el cargo,

\footnotetext{
${ }^{24}$ Cansino, César, Ortíz, Sergio y López, Moisés, "La rebelión del coro: la nueva Legislatura en México", Revista Diálogo y Debate de Cultura, año 1, núm. 3. Aluden a las dificultades legales de la integración de la LVII Legislatura, la distribución de las comisiones legislativas y el formato del tercer informe presidencial, entre otros puntos destacables.

${ }^{25}$ Desde 1997, ningún partido por sí mismo cuenta mayoría absoluta $(50 \%+1)$, lo que significa que tanto los órganos de dirección del Congreso General de los Estados Unidos Mexicanos, como las comisiones ordinarias, e incluso la Bicamaral que dirige los destinos del Canal del Congreso, están integradas por diputados o senadores que representan a sus fracciones asemejando la composición del Pleno Legislativo.

26 "Reglamento del Canal de Televisión del Congreso General de los Estados Unidos Mexicanos", op. cit.
} 
pues el seleccionado deberá contar con el grado mínimo de licenciatura ${ }^{27}$ y una amplia y probada experiencia en medios de comunicación.

Las atribuciones del titular de la Dirección General del Congreso van más allá de labores administrativas. El funcionario también está facultado para contratar y seleccionar a los mejores perfiles, aunque sólo se limita al aspecto técnico del medio de comunicación.

Por su parte, el consejo consultivo es un órgano colegiado, honorífico, ciudadano, plural y diverso. Está conformado por once integrantes de amplio y reconocido prestigio académico y profesional. Son electos por la Comisión Bicamaral, por mayoría de votos, a través de convocatoria pública abierta. Durarán en su encargo tres años con posibilidad de ratificación hasta por dos ocasiones. ${ }^{28}$

El consejo consultivo, como su nombre lo dice, es el enlace entre una estructura partidista y una que intenta aproximarse mayormente a la inclusión de la ciudadanía. El hecho de seleccionar a sus integrantes con alto prestigio académico y reconocimiento puede significar cierta imparcialidad en sus decisiones.

La posibilidad de someter a juicio reglas "para la expresión de las diversidades ideológicas étnicas y culturales" refleja la composición misma de lo que significa un México distinto, plural y diverso. De este modo, lo que se trasmite en el Canal del Congreso puede ser ya no un punto de vista unidireccional parcial y sesgado, sino incluyente y con apego a la nueva realidad nacional.

Un plus del consejo consultivo es que los integrantes no reciben algún tipo de remuneración. Su labor como enlace profesional con el Canal del Congreso muestra un avance significativo con respecto a lo que a la normatividad le toca. Sin embargo la limitante está precisamente en su labor consultiva y no deliberativa como la Comisión Bicamaral.

Por otro lado, el defensor de audiencia se designa por mayoría, a través de la Comisión Bicamaral y dura en su encargo tres años con la posibilidad de ser reelecto hasta por dos ocasiones. Si bien la designación no es por convocatoria pública, el titular debe contar con reconocido prestigio en el ámbito de las comunicaciones y no tener vínculos con partidos, agrupaciones políticas, cargo de elección popular o estar dentro de la administración pública. ${ }^{29}$ Dichos preceptos garantizan que el Consejo Consultivo y Defensor de

\footnotetext{
${ }^{27}$ Para analizar la profesionalización de los legisladores y de su equipo en la Cámara de Diputados o en el Congreso de la Unión, se necesita un análisis específico que aborde la evolución y el desarrollo de la institución en general y en particular de los legisladores que integran la Comisión Bicamaral y del equipo que trabaja en el Canal del Congreso; lo cual no es centro de investigación de este trabajo. Por tanto, sólo se presentan atisbos por profesionalizar la institución que la propia normatividad plasma, sin ahondar en el tema.

28 "Reglamento del Canal de Televisión del Congreso General de los Estados Unidos Mexicanos", op. cit. ${ }^{29}$ Ibidem.
} 
Audiencia no sean organismos parciales y sesgados, primariamente porque sus decisiones no deben estar ligadas a intereses de partidos políticos o, por lo menos, eso se espera.

La defensoría de audiencia sólo es exclusiva del Canal del Congreso. Esta estructura también aparece en diversos espacios de comunicación como Televisa, TV Azteca, Canal Once, entre otros. Estos espacios nacen de la reforma de telecomunicaciones de 2017 y de lo que plantea la Ley Federal de Telecomunicaciones y Radiodifusión: entre otras cosas, obliga a los concesionarios a contar con dicha figura. ${ }^{30}$

Como hemos analizado, la estructura general del Canal de Televisión del Congreso ha cambiado considerablemente. La Comisión Bicamaral que hasta hace poco contaba con todas las acciones de dirección dio paso a la especialización, a través de órganos que conjuntamente tienen la labor de diseñar las estrategias de comunicación y presentación de los planes de trabajo anuales, así como dar seguimiento de lo hecho, mediante los informes trimestrales. A su vez, el Consejo Consultivo y la Defensoría de Audiencia como estructura organizacional del Canal crean nuevos modelos de interacción ciudadana entre un organismo del Estado y sus gobernados.

En la estructura del Canal del Congreso - a excepción de la Comisión Bicamaral - la prioridad no es contar con personal que demuestre cierto nivel profesional, sino la "defensa de la expresión de las diversidades ideológicas étnicas y culturales" la representatividad de ambas cámaras y de los distintos grupos parlamentarios.

En este último punto, cabe preguntarnos si en aras de incluir a todas las fuerzas políticas en la Comisión Bicamaral se deja de lado la profesionalización y especialización y si esto representa un deliberado obstáculo para el desarrollo y crecimiento del propio Canal.

\section{Alcances y limitaciones del Canal del Congreso}

Conforme a lo establecido en el marco legal, una de las tareas principales del Canal del Congreso es la difusión de la información. En este sentido, al evaluar los informes de actividades del Congreso en su página web, sólo hay datos de 2014 al 2017, lo cual dificulta investigar y evaluar el trabajo en conjunto del Canal.

Tras buscar en distintas plataformas, encontramos que sólo se consiguen algunos de los informes trimestrales y anuales del Canal anteriores a 2014.

\footnotetext{
30 "Ley Federal de Telecomunicaciones y Radiodifusión", Diario Oficial de la Federación, 14 de julio, 2014. [Consulta: 10 de enero, 2017]. Disponible en: http://www.diputados.gob.mx/LeyesBiblio/pdf/ LFTR_311017.pdf
} 
En el informe trimestral de agosto-octubre de $2007,{ }^{31}$ se indica que el universo de televisión de cable de ese entonces ascendía a 855 compañías, de las cuales 658 trasmitían la señal del Canal del Congreso, esto es 78.61\% de cobertura.

En este sentido, el alcance del canal era amplio, pero sólo en televisión restringida. Datos publicados por el Instituto Nacional de Estadística Geografía e Informática (INEGI), de 2013, señalan que sólo 32.2\% de los hogares tienen acceso a televisión de paga. Si bien, el dato del informe del Canal del Congreso y los datos del INEGI tienen un desfase de siete años, nos sirve para afirmar que casi 70\% de los ciudadanos no tiene acceso a televisión de paga, y mucho menos al Canal del Congreso. El Canal inicia transmisiones abiertas desde el 5 de agosto de 2015.

En este mismo sentido, el apagón analógico iniciado en 2013 con la reforma a la ley de telecomunicaciones representó una dificultad mayor que no coadyuvó a fortalecer el alcance del Canal. ${ }^{32}$ Una vez que la totalidad del país migró de una tecnología a la otra, en 2015, se redujo significativamente la población que tenía acceso a televisión abierta. Como ejemplo, en la encuesta nacional sobre disponibilidad y uso de las tecnologías de la información en los hogares de 2016 realizada por INEGI, 92.7\% tiene algún televisor y de ellos sólo $32.4 \%$ de la población tiene un televisor digital. ${ }^{33}$

De acuerdo al informe de la empresa especializada en la medición de ratings y audiencias IBOPE AGB de México, en 2014, antes de su trasmisión abierta, el Canal del Congreso tuvo un promedio de 0.015 puntos de rating, equivalente a nueve mil televidentes en la república mexicana. De esta forma, el programa con mayor índice de audiencia del Canal del Congreso fue la serie de televisión Mesa de diálogo con un promedio de 0.01 puntos. Tan solo como contraste, el rating que IBOPE registró en el partido entre México y Camerún el 13 de junio de 2014, en el canal 2 de Televisa, fue de 17.4 puntos con casi nueve millones de televidentes frente a TV Azteca, con 14 puntos y visto por aproximadamente siete millones de televidentes. ${ }^{34}$

De esta forma, entre Televisa y TV Azteca tienen conjuntamente un rating de 31.4 puntos, equivalente a 16 millones de televidentes en un mismo horario frente a los 0.015 del Canal del Congreso con sus nueve mil televidentes.

\footnotetext{
31 "Informe del Canal del Congreso agosto-octubre, 2007", Canal del Congreso. Disponible en: legacy. canaldelcongreso.gob.mx/TTiK6sKV/nueva_imagen/informes/2007/ago-oct_2007/informe-agooct_2007.pdf

32 “Apagón analógico en México", Ciencia UANL. [Consulta: 12 de febrero, 2018]. Disponible en: cienciauanl. uanl.mx/?p=3733

33 "Encuesta nacional sobre disponibilidad y uso de la tecnología de la información en los hogares", INEGI, 2016. [Consulta: 12 de febrero, 2018]. Disponible en: www.inegi.org.mx/saladeprensa/boletines/2017/ especiales/esciales2017_03_02.pdf

${ }^{34}$ Villamil, Jenaro, "Televisa y TV Azteca, la disputa por el rating en el Mundial de Brasil", Revista Proceso, 17 de junio, 2014. Disponible en: http://www.proceso.com.mx/?p=374932
} 
En los tiempos de mayor teleaudiencia, las telenovelas mexicanas transmitidas por Televisa tuvieron en promedio 40 puntos del IBOPE. Como ejemplo de ello destaca La fea más bella, trasmitida en 2007, con 43 puntos. En la actualidad, el rating de las novelas no supera los 12 puntos, conforme a datos del Iвоpe, lo cual ha desatado una lucha de televisoras en contra del propio organismo de medición. ${ }^{35}$

La comparación entre el rating de partidos de futbol y telenovelas frente a lo que transmite el Canal del Congreso y su programa más representativo - a falta de datos con programación similar como el Canal Judicial - nos da un panorama muy preciso sobre los alcances de un canal y su respectiva programación.

Hoy en día, 27\% de la población no puede acceder a televisión abierta y, en caso de que cuente con televisión de paga y digital, sólo $40 \%$ puede acceder al Canal del Congreso. Finalmente, no porque 32\% cuente con televisión digital, significa que siga la programación del Canal del Congreso. Al realizar una búsqueda exhaustiva del rating del Canal del Congreso no hay información pública disponible, ni en los informes actuales, ni en su página web.

Los datos duros muestran que el principal objetivo del Canal del Congreso no se cumple; esto es, la difusión del trabajo parlamentario. De hecho, las limitantes del Canal del Congreso siguen siendo consecuencia de diversos aspectos. El primero, está relacionado con la forma en que se difunden y estructuran los programas del Canal. Éstos, como vimos, no tienen mayor impacto que en un grupo especializado en la temática parlamentaria.

El segundo aspecto es que la ciudadanía mexicana está escasamente interesada en las cuestiones de la vida pública. El tercero es que el cambio tecnológico aún limita los alcances y penetración del Canal en gran parte de la población. El cuarto es la lógica de la estructura organizacional del Canal, la cual tiene como principio incluir a todas las fuerzas partidistas en el mismo. El quinto factor es el poco impacto de la las contrataciones que exigen algún grado de licenciatura en los órganos de dirección del Canal, aunque éstos son sólo algunos de los aspectos.

Una encuesta sobre jóvenes, de entre 18 y 29 años, realizada por el Colegio de México dos semanas antes de las elecciones federales de $2012^{36}$ reconoce que $34 \%$ de jóvenes tiene gusto por las telenovelas, 32\% descarta contar con alguna ideología y menos de $1 \%$ se interesa por las secciones políticas de los diarios. Si bien, los jóvenes ven televisión, su interés inmediato no son los fenómenos políticos, sino diversos programas de entretenimiento.

\footnotetext{
${ }^{35}$ Villamil, Jenaro, “Televisa-TV Azteca: la guerra sucia del rating”, Revista Proceso, 28 de agosto, 2014. Disponible en: http://www.proceso.com.mx/?p=366731

36 "Jóvenes mexicanos prefieren las telenovelas a las ideologías: encuesta", Revista Proceso, 18 de agosto, 2013. Disponible en: http://www.proceso.com.mx/?p=350392
} 
En posteriores informes de actividades del Canal del Congreso que se revisaron hasta 2013, el apartado de ratings desaparece y el objetivo es no demostrar con datos duros lo que la población entera sabe: muy pocos ven el Canal del Congreso.

En cuanto al acceso a la página de internet del Canal del Congreso - que entró en funcionamiento en 2000 - en una revisión de seguimiento, en junio de 2006, recibió un total de 637864 visitas. En el informe de trabajo del Canal trimestral, de enero a marzo de 2009 se habían registrado 44000 181 visitas. ${ }^{37}$ De 2000 a 2006, cada año, en promedio, 91000 individuos acceden a la página de internet del Canal. Sin embargo, en las estadísticas de las plataformas digitales del Canal del Congreso, se señala que en todo 2017 el número de visitas al sitio del Canal en promedio mensual es de aproximadamente $41000 .^{38}$

En lo que respecta a números de reproducciones de videos en YouTube, en todo 2017, fue de 35 917. El número de seguidores de Facebook, en ese año, fue de 132 322. Sin embargo, en doce meses, el número de seguidores sólo aumentó por $10378 .{ }^{39}$ En comparación con páginas similares, como la del Canal Judicial, el número de seguidores en Facebook hasta enero de 2018, asciende a un total de 238295 de seguidores, con lo cual duplica la cantidad total de la misma red social que el Canal del Congreso posee.

El acceso a la red es una buena herramienta para difundir el trabajo del Canal, sin embargo datos de INEGI señalan que 53\% de los hogares del país no cuentan con una conexión a internet, ${ }^{40}$ lo cual deja fuera a un poco más de la mitad de la ciudadanía.

Como es de esperarse, los esfuerzos conjuntos en distintos medios de difusión como televisión y la red, a través de sus distintas plataformas, son un trabajo significativo para cumplir uno de sus objetivos, pero sin lograr el impacto y alcance deseado. A pesar de los obstáculos, nos preguntamos: ¿Qué se ha hecho respecto al Canal? ¿Hay programación innovadora? ¿Hay variedad de programación? Es por ello que, en el siguiente apartado, trataremos de analizar estas preguntas.

\footnotetext{
37 "Informe del canal de Congreso correspondiente a enero-agosto, 2009", Canal del Congreso. Disponible en: http://www.canaldelcongreso.gob.mx/TTiK6sKV/nueva_imagen/informes/2009/ene-marz_2009/ informe-ene-marz_2009.pdf

38 "Informe de Estadísticas de Plataformas Digitales del Canal de Congreso correspondiente al año 2017", Canal del Congreso. Disponible en: http://www.canaldelcongreso.gob.mx/transparencia/datos

${ }^{39}$ Ibidem.

${ }^{40}$ Instituto Nacional de Estadística Geografía e Informática. Disponible en: http://www.inegi.org.mx/ saladeprensa/aproposito/2017/internet2017_Nal.pdf
} 


\section{El CANAL DEL CONGRESO: PROGRAMACión}

Como hemos podido analizar, el Canal del Congreso se encuentra sumamente limitado en cuanto a la perspectiva de difusión. La reforma de telecomunicaciones representó un obstáculo más a su debe y, aunque desde 2015 a la fecha se trasmite el Canal por televisión abierta, existe un profundo desconocimiento de su existencia, además de que tiene una ínfima audiencia.

La programación y la innovación son elementos primordiales para la difusión del trabajo legislativo. Hoy en día, la competitividad en los medios de comunicación es sumamente atractiva para diversos gustos. La oferta, sin duda, es muy amplia, lo cual obliga al Canal a trabajar un poco más en la calidad de lo que se presenta y cómo se hace. Por tanto, es esencial que la población cautiva no sólo se mantenga, sino que haya nuevos televidentes con una oferta atractiva para su cotidianidad, de modo que se cumpla lo establecido por la norma.

Como puede observarse en el cuadro 1, la programación del Canal requiere innovación, lo acartonado sigue siendo la característica principal de sus transmisiones. Prevalecen los programas retransmitidos y diferidos que, a pesar de contar con edición, ésta no ayuda a mejorar lo que se presenta. Lo innovador sería la trasmisión en vivo, los errores que cometen los legisladores o incluso los cuestionamientos y debates de los grupos parlamentarios en temas tan importantes, diversos y de una complejidad tal, que darían luz $\mathrm{y}$ vida a un Canal casi inexistente.

En contrapartida, las trasmisiones de su canal hermano, el Canal Judicial, presentan las sesiones en vivo de los ministros de la Suprema Corte de Justicia de la Nación. Ello denota el valor de la transmisión en vivo y la preparación de los posicionamientos razonados, así como las afirmaciones de los participantes. 
Guadro 1. Programación del Canal del Congreso

\begin{tabular}{|c|c|c|c|c|}
\hline Hora & Programa & En vivo & Diferido & Retransmisión \\
\hline 00:00 & Noticias del Congreso & & $\checkmark$ & \\
\hline 01:00 & $\begin{array}{l}\text { Reunión de trabajo con Ildefonso Guajardo } \\
\text { Villareal, secretario de Economía, para } \\
\text { informar el estatus del Tratado Amplio y } \\
\text { Progresista de Asociación Transpacífico I }\end{array}$ & & & $\checkmark$ \\
\hline $04: 25$ & $\begin{array}{l}\text { Presentación del libro: La maternidad } \\
\text { subrogada }\end{array}$ & & & $\checkmark$ \\
\hline 06:05 & $\begin{array}{l}\text { Foro nacional: Hacia una iniciativa nacional } \\
\text { de supercómputo para incidir en los grandes } \\
\text { cambios y desafios de México, panel } 5\end{array}$ & & & $\checkmark$ \\
\hline 08:00 & Noticias del Congreso & & $\checkmark$ & \\
\hline 09:00 & $\begin{array}{l}\text { XXIV Reunión de la Comisión Parlamentaria } \\
\text { Mixta UE-México, inauguración }\end{array}$ & & $\checkmark$ & \\
\hline 09:55 & $\begin{array}{l}\text { Foro Hacia una iniciativa nacional de } \\
\text { supercómputo para incidir en los grandes } \\
\text { cambios y desafíos de México, parte } 2\end{array}$ & & & $\checkmark$ \\
\hline $11: 30$ & Sesión Ordinaria del Senado de la República & $\checkmark$ & & \\
\hline $15: 30$ & $\begin{array}{l}\text { Foro Políticas públicas como herramienta } \\
\text { fundamental para el cumplimiento de la } \\
\text { agenda 2030, parte } 2\end{array}$ & & $\checkmark$ & \\
\hline 17:00 & Avance Informativo & & $\checkmark$ & \\
\hline 17:05 & $\begin{array}{l}\text { Primer Simposio de Síndrome de Guillain } \\
\text { Barre y otras enfermedades neurológicas } 2018\end{array}$ & & $\checkmark$ & \\
\hline $18: 47$ & $\begin{array}{l}\text { XXIV Reunión de la Comisión Parlamentaria } \\
\text { Mixta UE-México, tema } 1\end{array}$ & & $\checkmark$ & \\
\hline 20:00 & Noticias del Congreso & & $\checkmark$ & \\
\hline 22:00 & $\begin{array}{l}\text { Especiales Arirang TV. Los secretos detrás del } \\
\text { éxito económico de Corea }\end{array}$ & & & $\checkmark$ \\
\hline $22: 30$ & $\begin{array}{l}\text { Noticiero científico y cultural iberoamericano. } \\
\text { Basura espacial }\end{array}$ & & & \\
\hline 23:00 & Historias de vida. Andrés Henestrosa, parte 2 & & & $\checkmark$ \\
\hline $23: 30$ & $\begin{array}{l}\text { Foro Políticas públicas como herramienta } \\
\text { fundamental para el cumplimiento de la } \\
\text { agenda 2030, inauguración }\end{array}$ & & & $\checkmark$ \\
\hline
\end{tabular}

Fuente: Elaboración propia a partir de datos de la página del Canal del Congreso. ${ }^{41}$

\footnotetext{
${ }^{41}$ http://www.canaldelcongreso.gob.mx/programacion 15 de Febrero, 2018.
} 
El cuadro anterior sólo presenta un programa en vivo del Canal del Congreso, la sesión ordinaria del Senado de la República. La transmisión en vivo de las sesiones ordinarias reflejan los periodos de mayor intensidad del Congreso de la Unión. Pero, de igual forma, se deberían trasmitir las sesiones de las más de cincuenta comisiones ordinarias, pues no por el hecho de estar fuera de periodos ordinarios de sesiones en ambas cámaras significa que no haya trabajo y vida en los órganos legislativos. ${ }^{42}$

De la programación informativa, se destaca el Noticiero del Congreso, que se trasmite de lunes a viernes de 20:00 a 21:00 horas con 65 emisiones en vivo por trimestre. ${ }^{43}$ Esto resalta la importancia de los programas con dichas características, pero aún están limitadas a un círculo cerrado, en cuanto a la capacidad de difusión.

Por otra parte, el Canal Judicial inició transmisiones el 29 de mayo de 2006, con una programación más dinámica y cercana a la ciudadanía en general. Como ejemplo, en 2007, se establecieron las bases para el programa Desafio furídico, mediante la adopción de un lenguaje sencillo, dirigido a los jóvenes con la intención de divulgar el conocimiento en la materia. ${ }^{44}$

Para 2010, más de quinientos sistemas de cable transmitían el Canal Judicial y, en 2018, aún sigue difundiéndose, a través de sistemas de cable de paga, sin que ello signifique mengua. En 2012, se adquirió equipo para transmitir el programa en alta definición y se firmó convenio con la televisora alemana Deutsche Welle. De esta forma, es evidente el esfuerzo por desarrollar una mejor programación basada en el diseño, innovación, página de internet, entre otras estrategias mediáticas que, en poco tiempo, colocaron al Canal como una mejor opción, a diferencia del Canal del Congreso.

En el cuadro 2, observamos una programación diseñada, preparada, articulada por pare del Canal Judicial. Podemos asegurar que la programación, producción, firmas de convenios con series, documentales, noticieros y el trabajo del pleno en vivo, hacen del Canal Judicial una alternativa creativa, innovadora y mucho más propositiva que el propio Canal del Congreso, a pesar de que aún no se trasmite su programación por televisión abierta.

\footnotetext{
42 "Ley Orgánica del Congreso General de los Estados Unidos Mexicanos", Diario Oficial de la Federación, 28 de diciembre, 2017.

${ }^{43}$ Informe del canal de Congreso de 2017,

http://legacy.canaldelcongreso.gob.mx/files/imagenes/Informes/INFORMETRIMESTRAL 2017_211107.pdf

${ }^{44}$ Suprema Corte de justicia de la Nación, Disponible en: https://www.scjn.gob.mx/transparencia/ Documents/Presidencia \%20-\%20Canal\%20Judicial.pdf
} 
Cuadro 2. Programación del Canal Judicial

\begin{tabular}{|c|c|c|}
\hline Hora & Programa & Título \\
\hline 06:00 & Sala de conciertos & $\begin{array}{l}\text { Ludwig van Beethoven, Concierto para violín y } \\
\text { orquesta en Re Mayor }\end{array}$ \\
\hline 07:00 & El foro & $\begin{array}{l}\text { III Congreso Internacional de Derecho Constitucional. } \\
\text { Conferencia: Constitucionalismo y Argumentación } \\
\text { parte } 13\end{array}$ \\
\hline 08:00 & Noticias Acceso Directo & Conducido por Óscar González \\
\hline 08:30 & $\begin{array}{l}\text { Noticias Internacionales } \\
\text { DW }\end{array}$ & $\begin{array}{l}\text { Desde Berlín, Alemania, una visión europea de la } \\
\text { información y de la economía mundial }\end{array}$ \\
\hline 09:00 & Perspectiva & $\begin{array}{l}\text { Tema: ¿El nuevo sistema penal acusatorio es la } \\
\text { solución? Conducido por Álvaro Altamirano }\end{array}$ \\
\hline $10: 00$ & $\begin{array}{l}\text { La visión de los } \\
\text { juzgadores }\end{array}$ & $\begin{array}{l}\text { Tema: Excelencia en la justicia. Conducido por } \\
\text { Fernando Córdova del Valle }\end{array}$ \\
\hline $11: 00$ & El Pleno en vivo & $\begin{array}{l}\text { La Suprema Corte de Justicia de la Nación delibera } \\
\text { ante las cámaras de televisión y en vivo los casos que } \\
\text { llegan al máximo tribunal de justicia }\end{array}$ \\
\hline $14: 30$ & Paraíso nórdico & $\begin{array}{l}\text { Documental sobre el sentido de la familia en los } \\
\text { países nórdicos en comparación al sentido familiar en } \\
\text { América }\end{array}$ \\
\hline $15: 00$ & Sharon Isbin trovadora & $\begin{array}{l}\text { Documental sobre la obra musical y trayectoria } \\
\text { artística de la talentosa guitarrista Sharon Isbin }\end{array}$ \\
\hline $16: 00$ & El Foro & $\begin{array}{l}\text { III Congreso Internacional de Derecho Constitucional. } \\
\text { Conferencia: Constitucionalismo y Argumentación } \\
\text { parte } 13\end{array}$ \\
\hline $17: 00$ & Veredictos de la historia & $\begin{array}{l}\text { Juicio histórico a Douglas MacArthur por las acciones } \\
\text { ejecutadas durante la Segunda Guerra Mundial }\end{array}$ \\
\hline 18:00 & Entre juristas & $\begin{array}{l}\text { Tema: Ediciones jurídicas. Vieja doctrina y nueva } \\
\text { doctrina. Conducido por Susana Barroso }\end{array}$ \\
\hline 19:00 & $\begin{array}{l}\text { Derecho a la protección } \\
\text { de la salud }\end{array}$ & $\begin{array}{l}\text { Programa que aborda el derecho a la protección de la } \\
\text { salud. Tema: La certificación de especialistas médicos }\end{array}$ \\
\hline 20:00 & $\begin{array}{l}\text { México en la memoria } \\
\text { del mundo }\end{array}$ & $\begin{array}{l}\text { Serie documental que aborda la historia patrimonial } \\
\text { de la colección de publicaciones periódicas de México } \\
\text { 1728-1917. Hemeroteca Nacional }\end{array}$ \\
\hline $20: 30$ & $\begin{array}{l}\text { Noticias Internacionales } \\
\text { DW }\end{array}$ & $\begin{array}{l}\text { Desde Berlín, Alemania, una visión europea de la } \\
\text { información y de la economía mundial }\end{array}$ \\
\hline $21: 00$ & Noticias Acceso Directo & Conducido por Erika Mora \\
\hline $21: 30$ & El Pleno (repetición) & $\begin{array}{l}\text { La Suprema Corte de Justicia de la Nación delibera } \\
\text { ante las cámaras de televisión y en vivo los casos que } \\
\text { llegan al máximo tribunal de justicia }\end{array}$ \\
\hline
\end{tabular}

Fuente: Elaboración propia a partir de la página del Canal Judicial. ${ }^{45}$

\footnotetext{
${ }^{45}$ https://canaljudicial.mx/es/Cartelera/20180215 15 de Febrero, 2018.
} 
En lo que respecta al terreno económico, el Canal Judicial, en 2010, recibió trece millones de pesos y, en 2011, catorce. Ya para 2017 el Canal Judicial recibió un presupuesto de cuarenta millones de pesos. ${ }^{46}$ Logró más recursos y una mayor calidad en su transmisión, producción y posproducción en general. Todo esto lo hizo con menos recursos de los que recibe el Canal del Congreso.

El Canal del Congreso, por su parte, entre 2008 y 2013, recibió un total de 170 millones de pesos y sólo en 2017 recibió 140 millones de pesos. ${ }^{47}$ En comparación con el presupuesto de 2017, el canal del Congreso recibió cien millones de pesos más que el Canal Judicial, lo cual, desde nuestro punto de vista, no ha influido en el progreso del Canal del Congreso, en cuanto a calidad e innovación.

En México, el Congreso tendría que replantearse no sólo la posibilidad de aumentar los recursos al Canal, sino hacer uso de los recursos lo más eficientemente posible. Una mejor canalización, bien orientada, planeada y estructurada de los recursos del Canal podría mejorar su calidad de transmisión, programación y, a su vez, cumplir su mandado normativo.

Por otra parte, el Canal del Congreso no sólo debería recibir presupuesto público, sino complementar su remuneración a través de otras fuentes. Como ejemplo, en Estados Unidos, el Canal del Congreso (C-Span) es sufragado por los sistemas de televisión por cable que funcionan en la Unión Americana. ${ }^{48}$ En el caso de México, el canal podría financiarse con la venta de espacios en el medio, así como la firma de convenios con otras televisoras nacionales e internacionales para mejorar sus contenidos y programación.

Este apartado muestra que la programación del Canal del Congreso, en comparación con otros medios similares, no es la más desarrollada en términos de producción y contenidos. A pesar de que cuenta con amplios recursos económicos, no ha generado una mayor visibilidad e impacto en la población en general.

\section{CONCLUSIÓN}

$\mathrm{Al}$ inicio de este trabajo nos planteamos determinar si, tras veinte años de existencia del Canal del Congreso, la normatividad, estructura, organización, programación y financiamiento entre otros elementos, contribuirían a mejorar no sólo el medio en sí mismo sino, a través de él, verificar el cambio de percepción que existe actualmente sobre el Congreso de la Unión y en particular de los legisladores.

\footnotetext{
${ }^{46}$ Aranda, Jesús, "El Canal Judicial cumple 11 años sin lograr su consolidación ni la señal abierta", Periódico La Fornada, 19 de junio, 2017. Disponible en: http://www.jornada.unam.mx/2017/06/19/politica/012n1pol 47 "Presupuesto Autorizado 2017", Dirección General del Canal del Congreso. Disponible en: http://legacy. canaldelcongreso.gob.mx/files/imagenes/Transparencia/InformacionRelevante/Presupuesto2017.pdf ${ }^{48}$ Celis, Darío, "Tiempo de negocios", Reforma, 29 de enero, 2004.
} 
Sin embargo, este recorrido que hemos realizado nos ha presentado una serie de circunstancias que han limitado seriamente los alcances del medio. Desde un análisis del desarrollo institucional de su normatividad - y por ende de las reglas de juego - , hoy en día, el Canal del Congreso debería posicionar a una institución tan relevante como el Poder Legislativo.

Los elementos que representan un obstáculo pueden enumerarse en tres puntos principales. Primero. La organización estructural del Canal del Congreso, dada a través de la Ley Orgánica del Congreso General de 1999, y el Reglamento del Canal de Televisión de 2005 obligan a que el órgano máximo de dirección (Comisión Bicamaral) esté integrado por los grupos parlamentarios más representativos de ambas cámaras. Esto para confrontar proyectos, intereses e ideologías de distintas fracciones parlamentarias. Esto atrofia los objetivos principales del Canal del Congreso.

Por otra parte, la propia norma coadyuva al trabajo de la institución, al exigir un grado académico de los integrantes de Dirección General y del Consejo Consultivo del Canal, pues se puede contar con cierto grado de experiencia y especialización en la materia. Este alcance queda opacado por la Comisión Bicamaral que tiene la facultad de destituir al titular de la Dirección si así lo desea.

Segundo, el avance del Canal al trasmitirse en televisión abierta quedó mermado con el apagón analógico de 2015. Por ello, su objetivo de difundir el trabajo legislativo quedó severamente estancado, pues no toda la ciudadanía cuenta con un televisor ad hoc a la tecnología. El avance tecnológico, a través de otras plataformas como Facebook o YouTube, ha logrado complementar lo que el propio canal hace, pero más de $50 \%$ de la población aún carece de acceso a la red.

Tercero, la programación cotidiana del Canal del Congreso, desde nuestro punto de vista, ha significado un estancamiento. Hace falta innovación, producción e inversión para mejorar lo transmitido cotidianamente. Los recursos con que se cuenta para la difusión, si bien son más en relación a otros medio como el Canal Judicial, no han producido programas dirigidos a los diversos sectores de la población. Los jóvenes son el sector que presenta más familiaridad con las nuevas tecnologías, pero también es el más exigente con respecto a la calidad de lo que se transmite y se produce.

Finalmente, vale la pena subrayar que el Canal del Congreso carece de estrategias concretas a largo plazo que impliquen mejoras en la producción y la difusión. Es necesario rediseñar un modelo institucional del Canal, no sólo para el desarrollo del mismo medio, sino para el Poder Legislativo, que va más allá de los intereses políticos. Por ello, el reto primordial del medio es ceder un poco de ese interés particular, a favor del interés general, en pro y beneficio de todos los involucrados. 


\section{B I BLIOGRAFÍ A}

“Apagón analógico en México", Ciencia UANL. [Consulta: 12 de febrero, 2018]. Disponible en: cienciauanl.uanl.mx/?p=3733

Aranda, Jesús, "El Canal Judicial cumple 11 años sin lograr su consolidación ni la señal abierta", Periódico La fornada, 19 de junio, 2017. Disponible en: http:// www.jornada.unam.mx/2017/06/19/politica/012n1pol

Béjar Algazi, Luisa, ¿Qué hacen los legisladores en México? Élites parlamentarias en México. Los presidentes de Comisiones, México, unam - Miguel Ángel Porrúa, 2009.

Bobillo, Francisco, "La opinión pública", Revista de Estudios Políticos, núm. 58.

Cansino, César, México en ruinas. Los saldos del panismo en el poder 2000-2012, México, Benemérita Universidad Autónoma de Puebla - Juan Pablos Editor, 2014.

Castells, Manuel. "La era de la información", Economía, Sociedad y Cultura. El poder de la identidad, vol. 2, México, Siglo XXI, 2004.

Celis, Darío, "Tiempo de negocios", Reforma, 29 de enero, 2004.

De la O López, Felipe, La percepción de las y los mexicanos en el Congreso de la Unión, México, Instituto Belisario Domínguez, 2017.

Durán Barba, Jaime, "La estrategia de la comunicación", en Roberto Izurieta (coord.), Estrategias de comunicación politica para campañas y gobiernos, México, The George Washington University - Benemérita Universidad Autónoma de Puebla, México, 2008.

"Encuesta nacional sobre disponibilidad y uso de la tecnología de la información en los hogares", inegi, 2016. [Consulta: 12 de febrero, 2018]. Disponible en: www. inegi.org.mx/saladeprensa/boletines/2017/especiales/esciales2017_03_02.pdf

"Estudios de opinión pública 2017 Canal del Congreso", Canal del Congreso, octubre, 2017. [Consulta: 17 de enero, 2017]. Disponible en: www.canaldelcongreso. gob.mx/transparencia/focalizada/ciudadanía

"Informe de Estadísticas de Plataformas Digitales del Canal de Congreso correspondiente al año 2017", Canal del Congreso. Disponible en: http://www.canaldelcongreso.gob.mx/transparencia/datos

"Informe del Canal del Congreso agosto-octubre, 2007”, Canal del Congreso. Disponible en: legacy.canaldelcongreso.gob.mx/TTiK6sKV/nueva_imagen/informes/2007/ago-oct_2007/informe-ago-oct_2007.pdf

"Informe del canal de Congreso correspondiente a enero-agosto, 2009", Canal del Congreso. Disponible en: http://www.canaldelcongreso.gob.mx/TTiK6sKV/ nueva_imagen/informes/2009/ene-marz_2009/informe-ene-marz_2009.pdf

Izurieta, Roberto, "La estrategia de comunicación", en Roberto Izurieta (coord.), Estrategias de comunicación politica para campañas y gobiernos, México, The George Washington University - Benemérita Universidad Autónoma de Puebla, 2008.

"Jóvenes mexicanos prefieren las telenovelas a las ideologías: encuesta", Revista Proceso, 18 de agosto, 2013. Disponible en: http://www.proceso.com.mx/?p=350392

"La mayoría de la población no sabe que existe el Canal del Congreso", Parametría, 2013. [Consulta: 16 de enero, 2018]. Disponible en: www.parametria.com. $\mathrm{mx} /$ casta_parametrica.php? $\mathrm{cp}=4641$

"Ley Federal de Telecomunicaciones y Radiodifusión", Diario Oficial de la Federación, 14 de julio, 2014. [Consulta: 10 de enero, 2017]. Disponible en: http://www. diputados.gob.mx/LeyesBiblio/pdf/LFTR_311017.pdf 
"Ley Orgánica del Congreso General de los Estados Unidos Mexicanos", Diario Oficial de la Federación, 3 de septiembre, 1999.

"Ley Orgánica del Congreso General de los Estados Unidos Mexicanos", Diario Oficial de la Federación, 31 de diciembre, 1999.

"Ley Orgánica del Congreso General de los Estados Unidos Mexicanos", Diario Oficial de la Federación, 28 de diciembre, 2017. Disponible en: http://www.diputados. gob.mx/LeyesBiblio/ref/locg.htm

Lujambio, Alonso, El poder compartido. Un ensayo sobre la democratización mexicana, México, Océano, 2000.

Mitofsky, "México: Confianza en Instituciones, 2015", Consulta. Disponible en: http://consulta.mx/index.php/estudios-e-investigaciones/mexico-opina/ item/575-confianza-eninstituciones

North, Douglass, Instituciones, cambio institucional y desempeño económico, México, Fondo de Cultura Económica, 1995.

"Presupuesto Autorizado 2017", Dirección General del Canal del Congreso. Disponible en: http://legacy.canaldelcongreso.gob.mx/files/imagenes/Transparencia/ InformacionRelevante/Presupuesto2017.pdf

"Reglamento del Canal de televisión del Congreso General de los Estados Unidos Mexicanos Artículo 3", Diario Oficial de la Federación, 8 de marzo, 2017. Disponible en: http://www.dof.gob.mx/nota_detalle.php?codigo $=5475476$ \&fecha $=08 / 03 / 2017$

Reyes Montes, María Cristina, O’Quínn Parrales, José Antonio, Morales y Gómez, Juan Miguel, Rodríguez Manzanares, Eduardo, "Reflexiones sobre la comunicación política", Espacios Públicos, vol. 14, núm. 30.

Suprema Corte de justicia de la Nación, Disponible en: https://www.scjn.gob.mx/ transparencia/Documents/Presidencia\%20-\%20Canal\%20Judicial.pdf

Villamil, Jenaro, "Televisa y TV Azteca, la disputa por el rating en el Mundial de Brasil", Revista Proceso, 17 de junio, 2014. Disponible en: http://www.proceso. com.mx/?p=374932

Villamil, Jenaro, "Televisa-TV Azteca: la guerra sucia del rating”, Revista Proceso, 28 de agosto, 2014. Disponible en: http://www.proceso.com.mx/?p=366731

Zaragoza Ramírez, Mario Alberto, "Democracia y comunicación política", en Felipe López Veneroni (coord.), El concepto de cultura politica y los medios de información en México, México, unam, 2009. 